\title{
A workshop for relatives of people with chronic mental illness
}

\author{
Richard Mullen, Bethlem Hospital; Paul Bebbington, MRC Social and \\ Community Psychiatry Unit, Institute of Psychiatry; and LIz KUIPERS, District \\ Services Centre, The Maudsley Hospital, London SE5 8AZ
}

The District Services Centre of the Maudsley Hospital deals with the care and rehabilitation of people with chronic mental illnesses. Three independent teams of mental health professionals comprise nurses, occupational therapists, psychiatrists, psychologists, and social workers. A multidisciplinary team approach is used in the assessment and management of patients. Most of the patients are either day-patients or 'supportive' patients who attend less frequently. The service is thus very much community based and orientated, and the support and involvement of close relatives in the care of the patients is seen as both necessary and desirable.

There are a number of ways in which this is encouraged. In this brief paper we describe one type of relatives' meeting, which is held once or twice a year. The chosen format seems both useful to staff and acceptable to the relatives, and should be easy to apply in other services and settings. The meetings are attended by both relatives and staff. The course of one such meeting, together with feedback from the relatives about its worth, is described here.

These meetings over the years have had a number of linked aims. They allow the relatives to get to know each other and to share their concerns about their role in caring for the patients. This helps break down the sense of isolation often experienced by relatives of the severely mentally ill. The meetings bring members of the team face to face with relatives in a pleasant, sociable and unthreatening setting and allow them to receive suggestions from the relatives about offering a better service. These aims are deliberately built into the format of the meetings, in particular the introductory exercise and the general degree of structure.

Close relatives known to be involved with patients of the team were invited to attend. Thirteen relatives eventually came to the one-and-a-half hour meeting. This was substantially less than on previous occasions, but the meeting had needed rescheduling at short notice because of bad weather. A brief welcome was made by the staff, and relatives and staff were invited to introduce themselves. In fact, most people at the meeting were known to each other, but as well as acting as a reminder the introduction also served as a means of breaking the ice. The staff then emphasised their desire for critical feedback about the functioning of the unit. Relatives were encouraged to consider general aspects of the service, rather than the specific problems of individual patients.

The meeting was then subdivided into two smaller groups, with the brief of raising issues and framing questions for later discussion. Tea and cakes were provided at this point. The staff provided any explanation and direction needed. The questions and suggestions that emerged were as follows:

(1) Could the standard of decor and cleanliness within the DSC be improved?

(2) Was transport to and from the DSC available?

(3) Could more recreational facilities for relatives and patients be provided?

(4) Could a private area be made available where patients and their relatives could meet?

(5) What was the standard of catering?

(6) Could a patients' holiday be arranged?

(7) Why did frequent changes in staffing occur (a reference to the biannual rotation of psychiatric registrars)?

(8) Were patients seen regularly by the doctor?

(9) What could be done to ensure regular attendance?

(10) Could more information be provided about side effects of medication?

(11) Was it possible to make the work done in occupational therapy and elsewhere more varied?

(12) How could relatives cope with and understand their unwell relatives' disruptive and worrying ways?

(13) What was the likely effect of health service financial problems?

After half-an-hour, the two groups joined up again and the points raised were listed on a board, so that they could be considered generally and staff could attempt to provide answers to the more answerable queries. As it turned out, at this meeting most questions were put to the consultant or the charge nurse, although this was not always the case in previous meetings. They tried to answer queries as honestly as possible, admitting ignorance where necessary. As 
might be expected from such a list of concerns, some of the feedback consisted of brief explanations of the limitations of financial resources and staff time. There was considerable reference to the chronic and often unpredictable nature of the illness concerned. The only issue which had not previously been considered by the staff was the lack of access for relatives to recreational facilities. It was felt by the relatives that such facilities would make a visit more like a normal social occasion and ease the progress of what are sometimes awkward meetings.

At the end of the meeting, relatives were asked to complete a short questionnaire relating to the meeting and its effect on their understanding of the way the service operated and of patients' problems, and on how they saw their own role in caring for them. All 13 returned usable questionnaires, although some had not answered all of the questions.

Eight out of 11 felt that their understanding of the way the service operated had improved as a result of the meeting, with one out of 13 believing that they now had a good or very good understanding. Seven out of 12 thought that their understanding of their relative's problems had also improved. Two out of 12 actually thought that their understanding of their relative's problems had worsened as a result of the meeting, but only one felt that their understanding was poor. Eight out of 13 felt that their general understanding of mental illness had improved, while none thought it worse. Seven out of 13 felt their understanding of their own role in the care of their relative had improved, while two felt it to be worse. All respondents thought that they would be fairly likely or very likely to be interested in further meetings.

\section{Comment}

A sizeable proportion of patients with long-standing mental illness live with their families. In our own service, $40 \%$ of men and $46 \%$ of women live with their families. Others live in close proximity with relatives providing a major supporting role. The execution of policies of community care will ensure that such arrangements become increasingly common. The burden that caring for relatives with longstanding mental illness imposes on families is well documented (Fadden $e t$ al, 1987). This influence is reciprocal: studies of expressed emotion demonstrate that aspects of family interaction can adversely affect the wellbeing of those with long-standing functional illness.

In the 1980s a number of successful interventions with relatives of patients with long-standing mental illness were described (Leff et al, 1982; Falloon et al, 1982; Hogarty et al, 1986). Principles of family management can thus be derived for use in routine clinical practice (Kuipers \& Bebbington, 1991). In particular, it is felt that all parties will benefit when clinicians are able to maintain a positive view of the potential contribution of relatives. Aside from the need for direct interventions of a skilled and structured sort, relatives require information to cast light on the patients' illness and their own predicament, and acknowledgement that their own role is both valuable and valued.

This brief report illustrates that simple meetings such as the one described are felt by relatives to be worthwhile and worth repeating. Although the content of the meeting may seem trivial in some respects, it clearly allowed relatives to feel involved and valued. Moreover, this format, with most members of the multidisciplinary team making themselves available to relatives in an informal but not unstructured setting, seems effective in breaking down constraints in the relatives. They certainly seemed able by the end of the meeting to voice complaints, although they did this in a constructive and friendly manner. Giving simple information to relatives about the nature and course of mental illness, and about the provision of services, may easily be overlooked by clinicians concerned with more urgent or esoteric aspects of assessment and management. This point is further underlined by the fact that the relatives at this meeting were involved with a particularly long-term group of patients.

The increasing trend towards community management of patients with severe mental illness places relatives at the forefront of the delivery of care. It behoves psychiatrists to respect and use this, and to forge the best possible working relationships with these other care givers.

\section{References}

Fadden, G. B., Bebbington, P. E. \& Kuipers, L. (1987) The burden of care: the impact of functional psychiatric illness on the patient's family. British Journal of Psychiatry, 150, 285-292.

FALLOON, I. R. H., BOYD, J. L., MCGiLL, C. W. et al (1982) Family management in the prevention of exacerbations of schizophrenia. A controlled study. New England Journal of Medicine, 306, 1437-1440.

HogarTy, G. E., ANDERSON, C. M., Reiss, D. J. et al (1986) Family psycho-education, social skills training and maintenance chemotherapy in the aftercare treatment of schizophrenia. I. One year effects of a controlled study on relapse and Expressed Emotion. Archives of General Psychiatry, 43, 633-642.

KuIPERS, L. \& BebBington, P. E. (1990). Working in Partnership: Clinicians and Carers in the Management of Longstanding Mental Illness, Oxford: Heinemann Medical.

LeFF, J. P., Kuipers, L., Berkowitz, R. et al (1982) A controlled trial of social intervention in schizophrenic families. British Journal of Psychiatry, 141, 121-134.

A full list of references is available on request from $\mathrm{Dr}$ Bebbington. 